\title{
A pH Sensitivity Control Method Using Hydrogen Annealing for Reference Field-Effect Transistors
}

\author{
Masato Futagawa*, Makoto Takahashi ${ }^{1}$, Keita Kamado를 \\ Makoto Ishida ${ }^{1,2}$ and Kazuaki Sawada ${ }^{1,2,3}$
}

\begin{abstract}
Head Office for "Tailor-Made and Baton-Zone" Graduate Course, Toyohashi University of Technology, 1-1, Hibarigaoka, Tempaku-cho, Toyohashi, Aichi 441-8580, Japan ${ }^{1}$ Department of Electrical and Electronic Information Engineering, Toyohashi University of Technology, 1-1, Hibarigaoka, Tempaku-cho, Toyohashi, Aichi 441-8580, Japan ${ }^{2}$ Electronics-Inspired Interdisciplinary Research Institute (EIIRIS), Toyohashi University of Technology, 1-1, Hibarigaoka, Tempaku-cho, Toyohashi, Aichi 441-8580, Japan ${ }^{3}$ Core Research for Evolutional Science and Technology, Japan Science and Technology Agency, 7, Gobancho, Chiyoda-ku, Tokyo 102-0076, Japan
\end{abstract}

(Received June 10, 2013; accepted August 21, 2013)

Key words: $\quad \mathrm{pH}, \mathrm{ISFET}$, REFET, hydrogen annealing, $\mathrm{pH}$ sensitivity, $\mathrm{Si}_{3} \mathrm{~N}_{4}$ film, CV measurement

Many studies have been carried out on the use of ion-sensitive field-effect transistor (ISFET) and reference FET (REFET) devices for $\mathrm{pH}$ measurements. In previous works, different materials were used for the sensing membranes of ISFET and REFET devices so that the $\mathrm{pH}$ sensitivity of the REFET was much less than that of the ISFET. In these cases, it proved difficult to cancel out the variation in the AC voltage component in the solution by synchronizing the output signals of the REFET and ISFET. Therefore, we put forward a new proposal, in which we use hydrogen annealing to decrease the $\mathrm{pH}$ sensitivity of a $\mathrm{Si}_{3} \mathrm{~N}_{4}$ film. Devices comprising $\mathrm{Si}_{3} \mathrm{~N}_{4}$ on $\mathrm{SiO}_{2}$ on n-type Si substrates were fabricated. The $\mathrm{pH}$ sensitivity of a device annealed in hydrogen for $20 \mathrm{~min}$ at 400 ${ }^{\circ} \mathrm{C}$ was reduced from 54.6 to $32.6 \mathrm{mV} / \mathrm{pH}$. A higher temperature annealing was largely ineffective in producing greater decreases in sensitivity, and the annealing affected only the surface of the Si3N4 film, not its interior. We succeeded in developing the fabrication technology for a device with low $\mathrm{pH}$ sensitivity to be used as a REFET.

\section{Introduction}

The measurement of $\mathrm{pH}$ using ion-sensitive field-effect transistors (ISFETs) ${ }^{(1-3)}$ is one of the most important techniques used to analyze biological and chemical reactions ${ }^{(4)}$ in medicine, environmental science, and agriculture. In these fields, in situ measurements are required to carry out long-term monitoring. However, the external reference electrodes used, such as $\mathrm{Ag} / \mathrm{AgCl}$ electrodes in $\mathrm{KCl}$ solution, ${ }^{(5,6)} \mathrm{Ag} / \mathrm{AgCl}$ electrodes ${ }^{*}$ Corresponding author: e-mail: futagawa@batonzone.tut.ac.jp 
without $\mathrm{KCl},{ }^{(7)}$ and Pt electrodes, ${ }^{(8)}$ are not without their problems; for example, the $\mathrm{KCl}$ solution for the $\mathrm{Ag} / \mathrm{AgCl}$ electrode needs to be replenished, while the $\mathrm{Ag} / \mathrm{AgCl}$ electrode without $\mathrm{KCl}$ cannot be used for long-term measurements. As an alternative, reference electrodes based on FETs, known as reference FETs (REFETs), have been studied. The required characteristic of the REFET is that it is less sensitive to $\mathrm{pH}$ than the ISFET. To achieve this, several types of $\operatorname{REFET}^{(9,10)}$ device with different sensing membranes have been proposed: a polyacrylate (polyACE) type, ${ }^{(11)}$ a polyvinyl chloride (PVC) type, ${ }^{(12,13)}$ a parylene type, ${ }^{(14)}$ and a $\mathrm{SiO}_{2}$ type. ${ }^{(15)}$ In all these cases, the sensing membranes of the ISFET and REFET were made of different materials, for example, an ISFET with a $\mathrm{Si}_{3} \mathrm{~N}_{4}$ membrane and a REFET with a PVC membrane. This made it difficult to cancel out the variation in the AC voltage component in the solution, because of the different threshold voltages and transconductances of the REFET and ISFET.

Our group has been investigating $\mathrm{pH}$ sensors for in situ continuous measurements of the activity of cells in medicine, ${ }^{(16,17)}$ the soil environment in agriculture, ${ }^{(18)}$ and the physical condition of domestic animals. ${ }^{(19,20)}$ However, external reference electrodes were used for the $\mathrm{pH}$ measurement, which restricted the measurement and experimental conditions for these in situ continuous measurements. Thus, we have been investigating a new approach in which a REFET with the same sensing membrane $\left(\mathrm{Si}_{3} \mathrm{~N}_{4}\right)$ and structure as the ISFET is used. The sensing membrane of the REFET is less sensitive to $\mathrm{pH}$ than that of the ISFET. However, the threshold voltages and transconductances of each device are the same, which makes it is easy to compensate for the variation in the AC voltage component. In this study, we proposed reducing the $\mathrm{pH}$ sensitivity of the REFET by hydrogen annealing. The $\mathrm{Si}_{3} \mathrm{~N}_{4}$ film was annealed and capacitance-voltage profiling was used to measure the variation in threshold voltage with $\mathrm{pH}$.

\section{Concept of Reducing the $\mathrm{pH}$ Sensitivity by $\mathrm{H}_{2}$ Annealing}

Many materials, such as $\mathrm{Si}_{3} \mathrm{~N}_{4}, \mathrm{Al}_{2} \mathrm{O}_{3}$, and $\mathrm{Ta}_{2} \mathrm{O}_{5}$, are used as the sensing membranes for ISFET pH sensors. ${ }^{(2,21)}$ In this study, we focused on $\mathrm{Si}_{3} \mathrm{~N}_{4}$ since this is compatible with Si complementary metal-oxide-semiconductor (CMOS) large-scale integrated (LSI) process technology.

According to the site-binding theory, silanol sites, $\mathrm{Si}-\mathrm{OH}$, and basic primary amine sites, Si- $\mathrm{NH}_{2}$, are present on the surface of $\mathrm{Si}_{3} \mathrm{~N}_{4}$ films. ${ }^{(22-24)}$ Both sites are more sensitive to hydrogen ions $\left(\mathrm{H}^{+}\right)$than to other ions, ${ }^{(24-26)}$ such as $\mathrm{Na}^{+}$and $\mathrm{K}^{+}$. Therefore, the $\mathrm{Si}_{3} \mathrm{~N}_{4}$ film can be used to monitor the $\mathrm{pH}$ of a solution. In this case, the sites easily bond with and easily dissociate from hydrogen: therefore, the changes in $\mathrm{pH}$ can be measured using the film.

Hydrogen annealing is often used in Si CMOS-LSI fabrication processes to reduce the defects between the gate oxide and the Si substrate. ${ }^{(27,28)}$ In this case, the defects are terminated by hydrogen atoms, which otherwise would be a source of increased variations in the threshold voltage of MOSFETs and give rise to leakage current in bipolar transistors.

We focused on this mechanism. If the $\mathrm{Si}-\mathrm{OH}$ and $\mathrm{Si}-\mathrm{NH}_{2}$ sites on the $\mathrm{Si}_{3} \mathrm{~N}_{4}$ surface were to be terminated by hydrogen atoms, would the $\mathrm{pH}$ sensitivity be decreased? If this mechanism can be realized with $\mathrm{Si}_{3} \mathrm{~N}_{4}$, a REFET with the same structure as an ISFET could be fabricated simultaneously with the ISFET using a CMOS-LSI process, as shown in Fig. 1. This is the structure we propose for a future device, and is based on our 


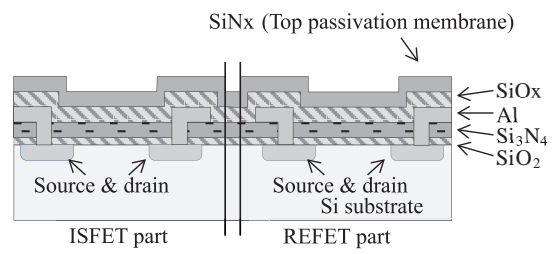

(a)

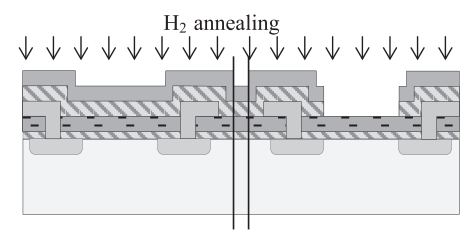

(c)

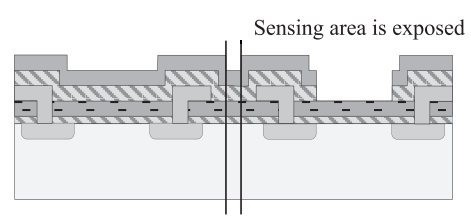

(b)

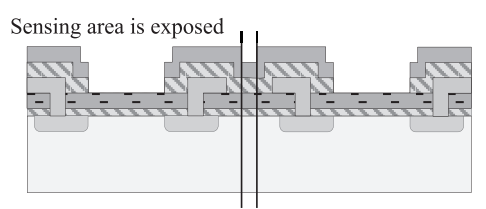

(d)

Fig. 1. Illustration of CMOS compatible LSI fabrication process for proposed integrated sensor comprising an ISFET and a REFET. (a) Conventional sensor structure after deposition of top $\operatorname{SiN}_{x}$ passivation layer. (b) Etching to surface of $\mathrm{Si}_{3} \mathrm{~N}_{4}$ to expose REFET sensing area. (c) $\mathrm{H}_{2}$ annealing to recover defect of interface between $\mathrm{Si}$ and $\mathrm{SiO}_{2}$ and to terminate surface of REFET sensing membrane. (d) Etching to expose ISFET sensing area.

conventional structure. The only additional step, compared with the ISFET fabrication process, is the formation of an aperture over the REFET sensing area, as shown in Fig. 1(b). In this study, to confirm the feasibility of this type of device, we performed basic experiments in which we measured the $\mathrm{pH}$ sensitivities of simple membranes with and without hydrogen annealing.

\section{Fabrication}

The sensing area of the ISFET/REFET was replicated by a simple structure fabricated using CMOS-LSI technology. Figure 2 shows the fabrication process. N-type Si of 3.5 $\Omega \mathrm{cm}$ was used as the substrate. First, a 52 -nm-thick layer of $\mathrm{SiO}_{2}$ was grown on the $\mathrm{Si}$ surface to anneal at $1000{ }^{\circ} \mathrm{C}$ with gas flows of $\mathrm{O}_{2}$ at $250 \mathrm{~L} / \mathrm{h}$ and $\mathrm{H}_{2}$ at $250 \mathrm{~L} / \mathrm{h}$, as shown in Fig. 2(a). Next, a 150-nm-thick $\mathrm{Si}_{3} \mathrm{~N}_{4}$ sensing membrane was deposited by thermal

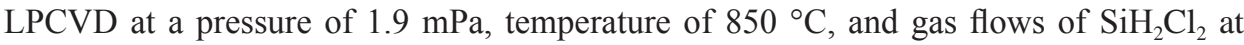
$200 \mathrm{sccm}$ and $\mathrm{NH}_{3}$ at $550 \mathrm{sccm}$, as shown in Fig. 2(b). In the next step, the samples were divided into two, such that some samples were annealed in hydrogen while other samples were unannealed, as shown in Fig. 2(c). The back sides of all the samples were abraded to break through the $\mathrm{SiO}_{2}$ and $\mathrm{Si}_{3} \mathrm{~N}_{4}$ on the backs of the chips, which were then attached to Au chip-mounted electrodes on a PCB substrate, as shown in Fig. 2(d). The contact between each chip and the electrode it was mounted on was ohmic. Finally, the sides of the chip and the chip mounting area were covered with an adhesive bond for waterproofing, as shown in Fig. 2(e). Figure 3 shows a photograph of a fabricated device. The lead wire is connected to the Si substrate through the chip-mounted electrode. For the $\mathrm{pH}$ sensitivity experiments, a $\mathrm{KCl}$ solution was dropped onto the surface of the chip, and a voltage was applied to the solution using a Ag/AgCl electrode. The experimental results are given in the next section. 


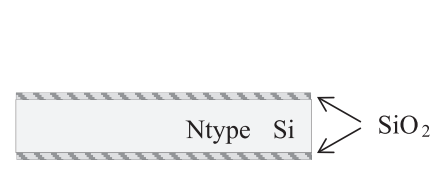

(a)

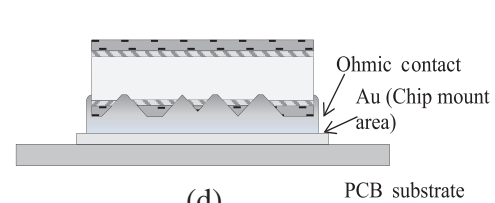

(d)

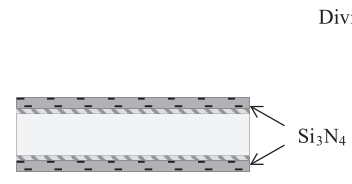

(b)
Divided into two samples with/without $\mathrm{H}_{2}$ annealing

$$
\mathrm{H}_{2} \text { annealing }
$$

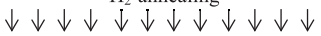

(c)

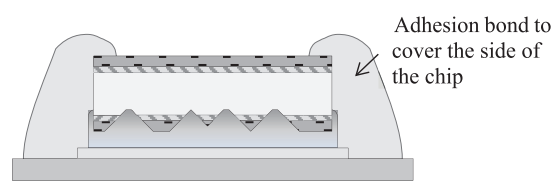

(e)

Fig. 2. Schematic diagrams showing fabrication process for experimental devices. (a) Thermal oxidation to grow 52-nm-thick $\mathrm{SiO}_{2}$ layer. (b) Deposition of 150 -nm-thick $\mathrm{Si}_{3} \mathrm{~N}_{4}$ layer by thermal LPCVD. (c) $\mathrm{H}_{2}$ annealing. (d) Chip mounted onto PCB substrate. (e) Adhesive bonding to cover sides and mounting area of chip.

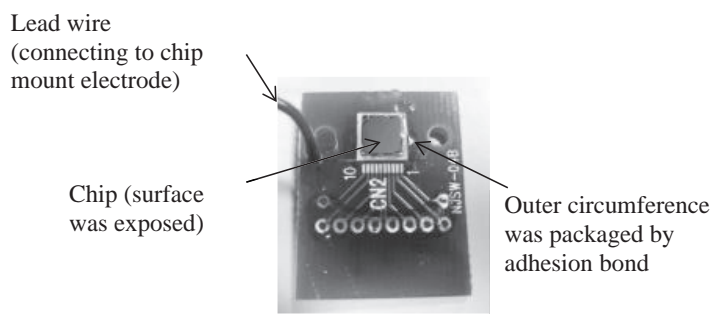

Fig. 3. Photograph of a fabricated device.

\section{Experimental Results and Discussion}

The $\mathrm{pH}$ sensitivity was measured by taking capacitance-voltage (CV) measurements with different $\mathrm{pH}$ buffer solutions. Figure 4 shows the experimental conditions for the CV measurements. Figure 4(a) shows a photograph of the setup, and Fig. 4(b) shows a schematic illustration of the measurement system. The CV measurements were carried out using an Agilent LCR meter operated at $100 \mathrm{~Hz}$. A bias voltage was applied between the solution and the Si substrate. When the voltage applied to the solution was about $-1.0 \mathrm{~V}$ above the threshold voltage, the silicon surface showed accumulation. Thus, the capacitance in accumulation was measured. In contrast, when the voltage applied to the solution was smaller than the threshold voltage, the surface showed inversion. Thus, the capacitance in inversion was measured. The threshold can be obtained from the ratio of these capacitances. ${ }^{(29)}$ Using this technique, the $\mathrm{pH}$ sensitivity can be monitored by measuring the shift in threshold voltage. ${ }^{30-32)}$

Figure 5(a) shows the results from the device without hydrogen annealing. The measurement results are shown by the ratio of the capacitance $C_{\text {mas }}$ to the capacitance at a potential of $2 \mathrm{~V}, \mathrm{C}_{\text {acc }}{ }^{(31)}$ where the device is in accumulation. The threshold voltage varies with the $\mathrm{pH}$ of the buffer solution. Figure 5(b) shows the relationship between $\mathrm{pH}$ and the shift in threshold voltage. The $\mathrm{Si}_{3} \mathrm{~N}_{4}$ film had sufficient $\mathrm{pH}$ sensitivity, close 


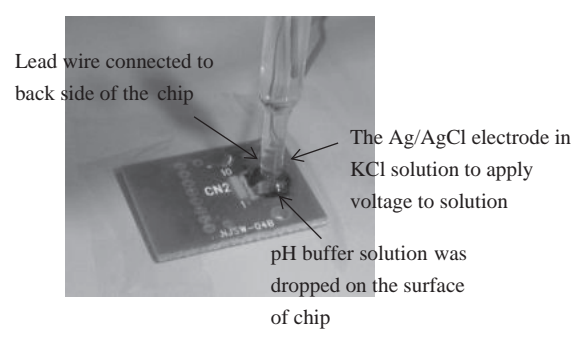

(a)

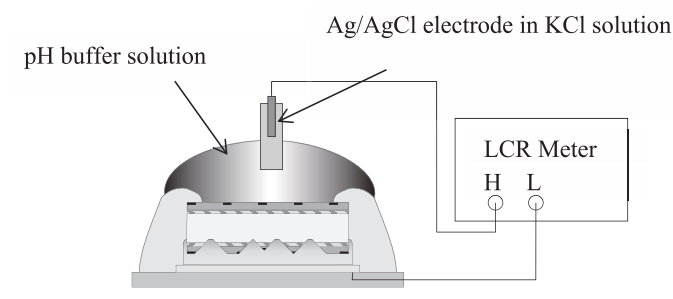

(b)

Fig. 4. Experimental setup for CV measurements. (a) Photograph of device and (b) illustration showing CV measurement setup.

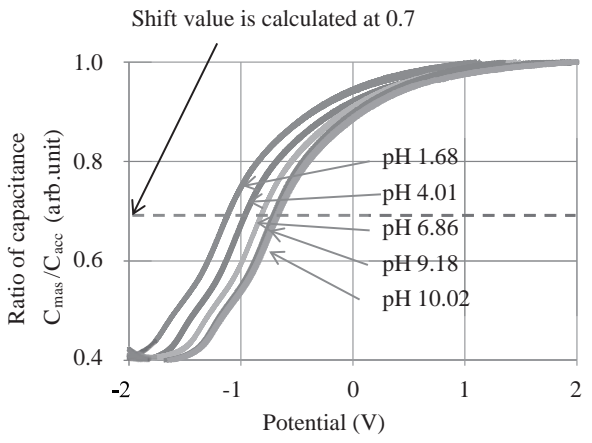

(a)

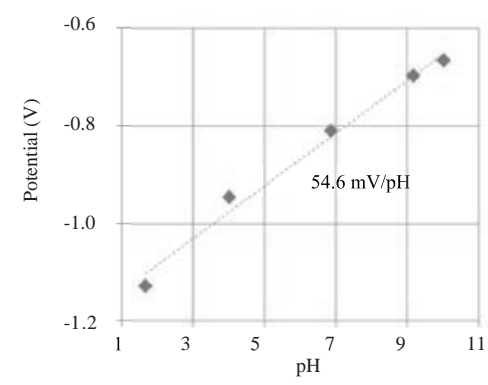

(b)

Fig. 5. CV measurement results showing variation in $\mathrm{pH}$ for device without hydrogen annealing.

to the ideal sensitivity given by the Nernst equation, to perform the hydrogen annealing experiments.

Figure 6 shows the variation in $\mathrm{pH}$ sensitivity with hydrogen annealing, which was carried out at $400{ }^{\circ} \mathrm{C}$, with gas flows of $\mathrm{H}_{2}$ at $0.4 \mathrm{~L} / \mathrm{min}$ and $\mathrm{N}_{2}$ at $10 \mathrm{~L} / \mathrm{min}$. The results show that with annealing, it was possible to reduce the $\mathrm{pH}$ sensitivity of the device to between 32.6 and $40.0 \mathrm{mV} / \mathrm{pH}$. In these experiments, the $\mathrm{pH}$ sensitivity decreased and then increased at longer annealing times. The mechanism of the increase will be analyzed and discussed in our future work.

Figure 7 shows a comparison of the $\mathrm{pH}$ sensitivities obtained with annealing temperatures of 400 and $500{ }^{\circ} \mathrm{C}$. In the CMOS-LSI process, the $\mathrm{H}_{2}$ annealing temperature is not more than $550{ }^{\circ} \mathrm{C}$, the temperature at which the $\mathrm{Si}$-Al eutectic forms. The thermal energy was varied by selecting two different annealing temperatures. However, the $\mathrm{pH}$ sensitivity after annealing at $500{ }^{\circ} \mathrm{C}$ did not decrease much further, confirming that the annealing temperature was not a dominant factor in reducing this.

To find the region affected by hydrogen annealing, the surface of the $\mathrm{Si}_{3} \mathrm{~N}_{4}$ film was lightly etched. After annealing for $20 \mathrm{~min}$ at $400{ }^{\circ} \mathrm{C}$, the sample was etched in BHF solution. The $\mathrm{pH}$ sensitivity of the device is shown in Fig. 8. The sensitivity of the lightly etched device recovered to around the initial sensitivity given in Fig. 6. This result confirms that hydrogen annealing to decrease the $\mathrm{pH}$ sensitivity only affects the surface of the $\mathrm{Si}_{3} \mathrm{~N}_{4}$, as expected. 

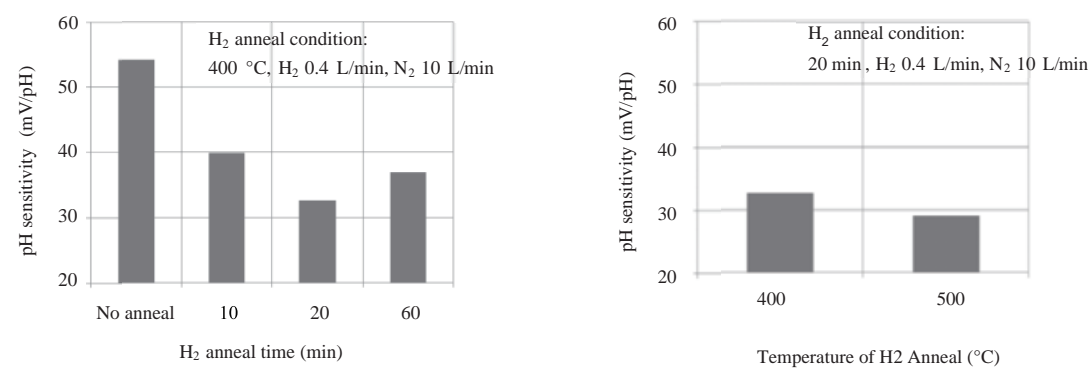

Fig. 6 (left). Experimental results for devices with and without $\mathrm{H}_{2}$ annealing, showing variation in $\mathrm{pH}$ sensitivity with annealing time.

Fig. 7 (right). Comparison of $\mathrm{pH}$ sensitivity of devices with different annealing temperatures.

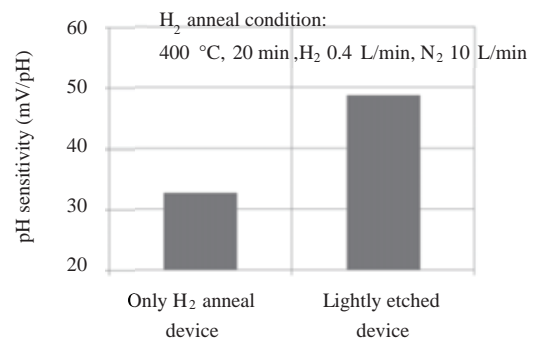

Fig. 8. Change in $\mathrm{pH}$ sensitivity of an annealed device after being lightly etched.

Experiments to establish whether the $\mathrm{pH}$ sensitivity could be decreased by $\mathrm{H}_{2}$ annealing were performed and the result was confirmed. However, the resulting decrease in the $\mathrm{pH}$ sensitivity of the REFET was insufficient for this to be used in a $\mathrm{pH}$ sensor. Therefore, we will continue to perform further experiments in order to develop this type of advanced $\mathrm{pH}$ sensor.

\section{Conclusions}

We proposed a new method of decreasing the $\mathrm{pH}$ sensitivity of $\mathrm{Si}_{3} \mathrm{~N}_{4}$ so that it could be used as the sensing membrane of a REFET, which is used as the reference electrode in a pH sensor. Experimental devices comprising $\mathrm{Si}_{3} \mathrm{~N}_{4}$ on $\mathrm{SiO}_{2}$ on n-type $\mathrm{Si}$ substrates were fabricated. The $\mathrm{pH}$ sensitivity of a chip annealed for $20 \mathrm{~min}$ in hydrogen at $400{ }^{\circ} \mathrm{C}$ was reduced from 54.6 to $32.6 \mathrm{mV} / \mathrm{pH}$. Using a higher annealing temperature was ineffective in reducing this further. Annealing affected only the surface, not the interior of the $\mathrm{Si}_{3} \mathrm{~N}_{4}$ film. We succeeded in developing the fabrication technology for a REFET device with low $\mathrm{pH}$ sensitivity. 


\section{Acknowledgements}

This work was partially supported by the Global COE Program "Frontiers of Intelligent Sensing" from the Ministry of Education, Culture, Sports, Science and Technology, Coalition Research Program for Agriculture and Engineering, a Grant-inAid for Research and Development for Innovation in Community from the Ministry of Economy, Trade and Industry, a Grant-in-Aid for Scientific Research from the Japan Society for the Promotion of Science, and a Grant-in-Aid for Scientific Research S (No. 24226010), Launch of IT Integration-based New Social System Development and Demonstration Projects from the New Energy and Industrial Technology Development Organization.

\section{References}

1 P. Bergveld: IEEE Trans. Biomed. Eng. 17 (1970) 70.

2 M. Esashi and T. Matsuo: IEEE Trans. Biomed. Eng. 25 (1978) 184.

3 K. Nakazato: Sensors 9 (2009) 8831.

4 T. Hattori, Y. Masaki, K. Atsumi, R. Kato and K. Sawada: Anal. Sci. 26 (2010) 1039.

5 A. van den Berg, A. Grisel, H. H. van den Vlekkert and N. F. de Rooij: Sens. Actuators, B 1 (1990) 425.

6 I-Y. Huang and R.-S. Huang: Thin Solid Films 406 (2002) 255.

7 D. Harame, J. Shott, J. Plummer and J. Meindl: IEDM Tech. Dig., 1981, p. 467.

8 M. B. Ali, R. Kalfat, H. Sfihi, J. M. Chovelon, H. B. Ouada and N. Jaffrezic-Renaulta: Sens. Actuators, B 62 (2000) 233.

9 P. Bergveld: Biosensors 2 (1986) 15.

10 P. Bergveld, A. van den Berg, P. D. van der Wal, M. Skowronska-Ptasinska, E. J. R. Sudhölter and D. N. Reinhoudt: Sens. Actuators 18 (1989) 309.

11 M. Skowronska-Ptasinska, P. D. van der Wal, A. van den Berg, P. Bergveld, E. J. R. Sudhölter and D. N. Reinhoudt: Anal. Chim. Acta. 230 (1990) 67.

12 A. Errachid, J. Bausells and N. Jaffrezic-Renaultb: Sens. Actuators, B 60 (1999) 43.

13 C.-S. Lai, C.-E. Lue, C.-M. Yang, M. Dawgul and D. G. Pijanowska: Sensors 9 (2009) 2076.

14 T. Matsuo, H. Nakajima, T. Osa and J. Anzai: Sens. Actuators, B 9 (1986) 115.

15 B. Palán, F. V. Santos, J. M. Karam, B. Courtois and M. Husák: Sens. Actuators, B 57 (1999) 63.

16 T. Hizawa, K. Sawada, H. Takao and M. Ishida: Sens. Actuators, B 117 (2006) 509.

17 F. Dasai, M. Futagawa, D. Suzuki, R. Otake, M. Ishida and K. Sawada: IEEE APCOT 2012, Nanjing, China, July 8-11, 2012.

18 M. Futagawa, T. Iwasaki, H. Murata, M. Ishida and K. Sawada: Sensors 12 (2012) 8338.

19 M. Futagawa, T. Iwasaki, Mi. Ishida, K. Kamado, Ma. Ishida and K. Sawada: Jpn. J. Appl. Phys. 49 (2010) 04DL12-1.

20 M. Futagawa, Mi. Ishida, Ma. Ishida and K. Sawada: IEEJ Trans. Electr. Electron. Eng. 6 (2011) 93.

21 L. Bousse and P. Bergveld: Sens. Actuators 6 (1984) 65.

22 T. Matsuo and M. Esashi: Sens. Actuators 1 (1981) 77.

23 D. L. Harame, L. J. Bousse, J. D. Shott and J. D. Meindl: IEEE Trans. Electron Devices 34 (1987) 1700 .

24 M.-N. Niu, X.-F. Ding and Q.-Y. Tong: Sens. Actuators, B 37 (1996) 13.

25 L. Bousse, N. F. de Rooij and P. Bergveld: IEEE Trans. Electron Devices 30 (1983) 1263. 
26 C. D. Fung, P. W. Cheung and W. H. Ko: IEEE Trans. Electron Devices 33 (1986) 8.

27 D. L. Griscom: J. Electron. Mater. 21 (1992) 763.

28 N. Sato and T. Yonehara: Appl. Phys. Lett. 65 (1994) 1924.

29 S. M. Sze: Physics of Semiconductor Devices (Wiley, New York, 1981) 2nd ed., p. 371.

30 T. Mikolajick, R. Kühnhold and H. Ryssel: Sens. Actuators, B 44 (1997) 262.

31 A. A. Poghossian: Sens. Actuators, B 44 (1997) 551.

32 A. Poghossian, D.-T. Mai, Y. Mourzina and M. J. Schöning: Sens. Actuators, B 103 (2004) 423. 